\title{
Transcriptional Coactivator PGC-1 $\alpha$ Binding to Newly Synthesized RNAvia CBP80: A Nexus for Co- and Posttranscriptional Gene Regulation
}

\author{
Xavier Rambout, ${ }^{1,2}$ Hana Cho, ${ }^{1,2}$ and Lynne E. Maquat ${ }^{1,2}$ \\ ${ }^{1}$ Department of Biochemistry and Biophysics, School of Medicine and Dentistry, \\ ${ }^{2}$ Center for RNA Biology, University of Rochester, Rochester, New York 14642, USA \\ Correspondence: lynne_maquat@urmc.rochester.edu
}

\begin{abstract}
Mammalian cells have many quality-control mechanisms that regulate protein-coding gene expression to ensure proper transcript synthesis, processing, and translation. Should a step in transcript metabolism fail to fulfill requisite spatial, temporal, or structural criteria, including the proper acquisition of RNA-binding proteins, then that step will halt, fail to proceed to the next step, and ultimately result in transcript degradation. Quality-control mechanisms constitute a continuum of processes that initiate in the nucleus and extend to the cytoplasm. Here, we present published and unpublished data for protein-coding genes whose expression is activated by the transcriptional coactivator PGC- $1 \alpha$. We show that PGC- $1 \alpha$ movement from chromatin, to which it is recruited by DNA-binding proteins, to CBP 80 at the 5 ' cap of nascent transcripts begins a series of co- and posttranscriptional quality- and quantity-control steps that, in total, ensure proper gene expression.
\end{abstract}

\section{CBP80}

Cap-binding protein 80 (CBP80) and CBP20 constitute the heterodimer called the cap-binding complex $(\mathrm{CBC})$. CBP80, via CBP20, binds the $\mathrm{m}^{7} \mathrm{G} 5^{\prime}$ cap of nascent RNAs, such as precursors to mRNAs (pre-mRNAs), as they are synthesized by RNA polymerase II (RNAPII) (Lejeune et al. 2002; Listerman et al. 2006; Glover-Cutter et al. 2008). Whereas CBP20 directly binds the cap, CBP80 increases the affinity of CBP20 for the cap and also serves as a docking platform for numerous RNA processing factors (for review, see Gonatopoulos-Pournatzis and Cowling 2014). Over the years, the CBC has been found to bind, remodel, and regulate the fate of proteincoding transcripts during their synthesis and processing in the nucleus, export from the nucleus to the cytoplasm and, as our laboratory has found in studies of mammalian cells, cytoplasmic "pioneer" rounds of translation that, depending on the mRNA, may be coupled to nonsensemediated mRNA decay (NMD) (for reviews, see Gonatopoulos-Pournatzis and Cowling 2014; Kurosaki et al. 2019). For mRNAs that are not degraded by NMD, the $\mathrm{CBC}$ is subsequently replaced by another cap-binding protein, eukaryotic translation initiation factor 4E (eIF4E) (Lejeune et al. 2002), which typically supports the bulk of cellular translation (Pelletier and Sonenberg 2019).

Our laboratory's continuing interest in the $\mathrm{CBC}$ and, in particular, CBP80 function began with our finding that CBP80 promotes NMD. The best-characterized NMD targets harbor at least one exon-junction complex (EJC), deposited as a consequence of pre-mRNA splicing (Le Hir et al. 2000), on their 3' untranslated region (3' UTR).
$3^{\prime}$-UTR EJC-dependent NMD initiates while the $5^{\prime}$ cap is still bound by the $\mathrm{CBC}$ during what we have called pioneer rounds of translation (Ishigaki et al. 2001; Hwang et al. 2010). These rounds occur on the cytoplasmic side of the nuclear envelope, as soon as newly synthesized mRNAs can be accessed by cytoplasmic ribosomes (Trcek et al. 2013). Depending on the length of the open reading frame (ORF) and efficiency of translation initiation, pioneer rounds can involve more than one associated ribosome translating the ORF, which is consistent with the decay steps of NMD requiring inhibition of further translation initiation events (Isken et al. 2008; Hoek et al. 2019).

Our studies have shown that CBP80 promotes NMD not only as a translation initiation factor but also as a choreographer of mRNA-protein rearrangements. Should a 3'-UTR EJC remain downstream from a ribosome after translation termination, as is often the scenario when translation terminates at a premature termination codon (PTC), then CBP80 escorts the essential NMD factor UPF1, which is an ATP-dependent RNA helicase, together with the UPF1 kinase, SMG1, first to the translation termination factors bound at the PTC and subsequently to the 3'-UTR EJC (Hosoda et al. 2005; Hwang et al. 2010). Details of these and other steps involving cytoplasmic functions of CBP80 and the CBC have been recently reviewed (Kurosaki et al. 2019).

The $\mathrm{CBC}$ also functions in the nucleus, where it promotes gene transcription, pre-mRNA splicing, and nuclear mRNA export. Of these functions, how the $\mathrm{CBC}$ promotes transcription is not well-characterized, especially in higher eukaryotes. To date, CBC-dependent transcription re-initiation has been established for Saccharomyces cerevisiae

(C) 2019 Rambout et al. This article is distributed under the terms of the Creative Commons Attribution-NonCommercial License, which permits reuse and redistribution, except for commercial purposes, provided that the original author and source are credited. 
(Lahudkar et al. 2011; Li et al. 2016a) and Drosophila melanogaster (Kachaev et al. 2019). Additionally, CBCdependent transcription elongation has been shown for S. cerevisiae (Hossain et al. 2013; Lidschreiber et al. 2013) and mammalian cells (Lenasi et al. 2011). Notably, CBC-mediated control of transcription appears to be genespecific, and gene-specific molecular determinants of CBC-mediated re-initiation of transcription have been identified (Lahudkar et al. 2011; Li et al. 2016a; Kachaev et al. 2019). However, how the CBC recruits elongation factors, such as the positive transcription elongation factor $\mathrm{P}-\mathrm{TEFb}$ and the cyclin-dependent kinase CDK12, on specific genes is unknown (Lenasi et al. 2011; Hossain et al. 2013; Lidschreiber et al. 2013).

\section{THE CBP80-BINDING MOTIF OF PGC-1 PROTEINS}

Given our long-standing interest in the mechanistic continuum of nuclear and cytoplasmic RNA processes, we aimed to extend our largely cytoplasmic studies of mammalian-cell CBP80 to the nucleus. To begin, we interrogated a previously published yeast two-hybrid screen for human cDNAs encoding proteins that directly interact with human CBP80 (Kataoka et al. 1995). Among CBP80-binding partners identified were nuclear capbinding protein (NCBP)-interacting protein 1 (NIP1) and NIP2, which were later renamed, respectively, CBP20 and PPAR $\gamma$ coactivator 1beta (PGC-1 $\beta$, in which PPAR is an abbreviation for peroxisome proliferator-activated receptor). PGC- 1 proteins PGC- $1 \beta$ and PGC- $1 \alpha$ are established transcriptional coactivators recruited to particular DNA promoters and enhancers via numerous transcription factors, including nuclear receptors, so as to regulate many aspects of metabolism and the anti-inflammatory response (see, e.g., Correia et al. 2015; Martínez-Redondo et al. 2015). However, the molecular mechanisms governing their transcriptional activities have been understudied in view of their importance to cellular and organismal physiology.

There are obvious gaps in our current understanding of how DNA-associated and/or RNA-associating proteins in mammalian cells coordinate the various steps involved in protein-coding gene expression (Rambout et al. 2016, 2018). To address gaps that involve CBP80, we began by characterizing the physical interaction between CBP80 and PGC-1 $\beta$ (Cho et al. 2018). Using GST pull-downs, we mapped the CBP80-binding domain of PGC-1 $\beta$ to its extreme carboxyl terminus. We then solved the X-ray crystal structure of this terminus in complex with cap-bound CBC to reveal that a 9 -amino acid $\alpha$-helix of PGC-1 $\beta$ was positioned on a lipped shelf consisting of the two aminoterminal-most $\alpha$-helices of CBP80 (Fig. 1A; modified from Cho et al. 2018). We named the $\alpha$-helix of PGC-1 $\beta$ the CBP80-binding motif (CBM). In vitro fluorescence polarization competition assays showed that all five residues of the PGC-1 $\beta$ CBM directly contacting CBP80 in the $\mathrm{X}$-ray crystal structure are required for CBP80 binding (Cho et al. 2018). Given that these residues are conserved in PGC- $1 \beta$ and PGC- $1 \alpha$ of every mammalian species we examined, and considering that a number of PGC- $1 \alpha$ target genes - both protein-coding genes and their associated enhancers - had been identified in cells of interest to us (i.e., mouse C2C12 myoblasts [MBs]) (Aguilo et al. 2016), we set out to determine if PGC- $1 \alpha$ serves as an important transcriptional cofactor for, initially, the $\mathrm{CBC}$-dependent control of PGC-1 $\alpha$-responsive gene expression.

Prior to our work, PGC-1 $\alpha$ was known to promote gene transcription through at least two distinct mechanisms. In one mechanism, PGC- $1 \alpha$ tethers via its aminoterminal activation domain histone acetyl transferases, such as the CREB-binding protein/E1A-binding protein $\mathrm{CBP} / \mathrm{p} 300$ and the proto-oncogene tyrosine-protein kinase SRC-1, presumably to loosen local chromatin compaction and facilitate the formation of the transcription pre-initiation complex at target-gene transcription start sites (Puigserver et al. 1999; Wallberg et al. 2003). In a second mechanism, the carboxy-terminal arginine-serine rich (RS) domain of PGC- $1 \alpha$ directly binds the MED1 subunit of the master transcriptional regulator Mediator (Wallberg et al. 2003; Chen et al. 2009). Although Mediator has been shown to play many roles in transcription (Allen and Taatjes 2015), the mechanism by which PGC- $1 \alpha$ binding to MED1 promotes gene transcription is unclear. In addition to its transcriptional coactivator function, PGC- $1 \alpha$ acts as a transcriptional repressor, as illustrated by its binding to and inhibition of the transcription factor XBP1s (Lee et al. 2018), and also as an alternative splicing factor (Monsalve et al. 2000; Martínez-Redondo et al. 2016).

\section{THE PGC-1 $\alpha$ CBM PROMOTES TARGET- GENE TRANSCRIPTION}

Consistent with the emerging view that chromatinassociated RNA-binding proteins can regulate gene transcription (Xiao et al. 2019), we showed that PGC-1 $\alpha$ recruitment via its $\mathrm{CBM}$ to the $\mathrm{CBC}$ at the $5^{\prime}$ cap of nascent pre-mRNAs and their associated enhancer RNAs (eRNAs), is critical for the activation of the majority of its target genes. These conclusions are supported by three lines of evidence. First, the co-immunoprecipitation (coIP) of C2C12-MB pre-mRNAs produced by PGC- $1 \alpha$-activated genes with FLAG-tagged wild-type (WT) PGC-1 $\alpha$ (FLAG-PGC-1 $\alpha(\mathrm{WT})$ ) is lost when RNase $\mathrm{H}$ is directed to cleave $6 \mathrm{nt}$ downstream from their $5^{\prime}$ caps (Fig. 1B-D; modified from Cho et al. 2018). Second, the co-IP of CBP80 as well as PGC-1 $1 \alpha$ up-regulated mRNAs and eRNAs with FLAG-PGC- $1 \alpha(\mathrm{WT})$ is lost when the CBM of FLAG-PGC- $1 \alpha(\mathrm{WT})$ is deleted (PGC- $1 \alpha(\Delta \mathrm{CBM})$ ) (Fig. 1B-E; modified from Cho et al. 2018; see Cho et al. 2018 for data on eRNAs). Third, $\sim 80 \%$ of genes responsive to $\mathrm{PGC}-1 \alpha$-mediated transcriptional activation require the $\mathrm{PGC}-1 \alpha \mathrm{CBM}$, as evidenced from transcriptome-wide RNA-seq data comparing WT C2C12 MBs, $\mathrm{C} 2 \mathrm{C} 12 \mathrm{MBs}$ in which cellular PGC-1 $\alpha$ is knocked down (PGC-1 $\alpha-\mathrm{KD}$ C2C12 MBs), and C2C12 MBs in which cellular PGC- $1 \alpha$ was replaced by FLAG-PGC- $1 \alpha(\mathrm{WT})$ 
A

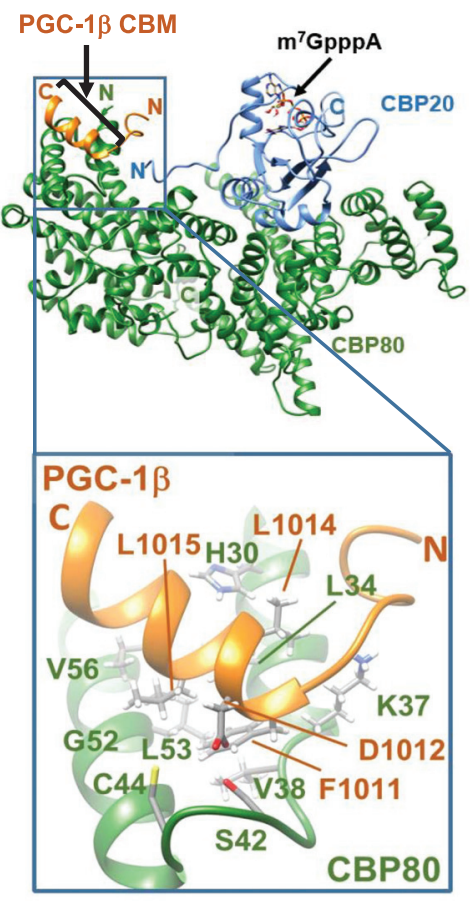

B

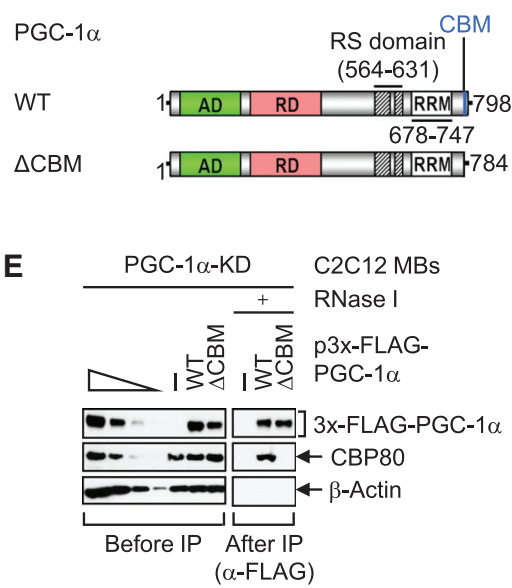

C?

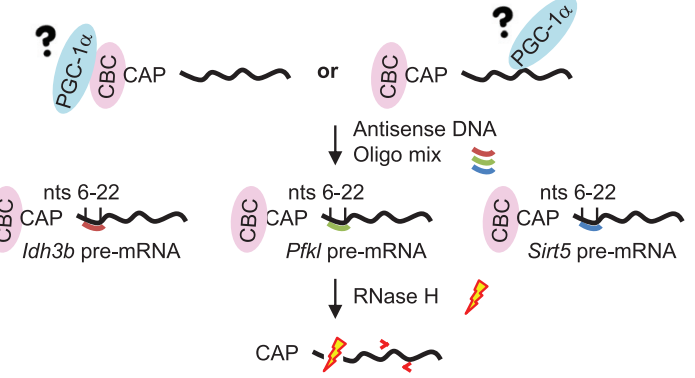

D

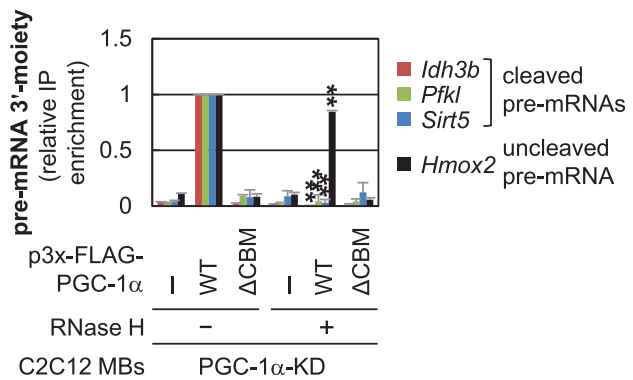

$\mathbf{F}$

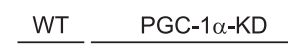

C2C12 MBs

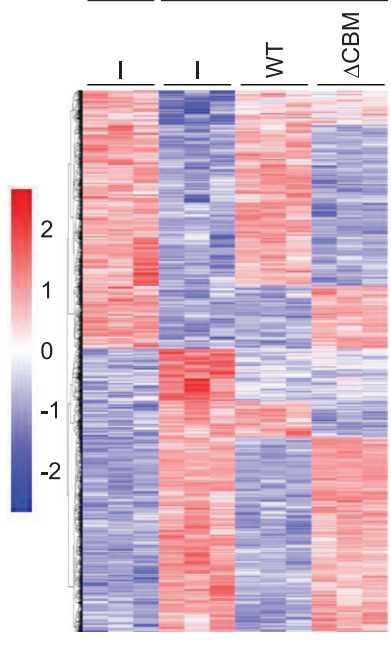
p3x-FLAG-PGC-1 $\alpha$

Cluster \#1 (140 genes)

Cluster \#2 (677 genes)

Cluster \#3 (260 genes)

Cluster \#4 (208 genes)

Cluster \#5 (155 genes)

Cluster \#6 (817 genes)

Figure 1. CBP80 binding to the carboxy-terminal end of the PGC-1 family of transcriptional coactivators can promote target-gene transcription (modified from Cho et al. 2018). (A) Crystal structure at $2.68 \AA$ resolution of the carboxy-terminal end of human PGC-1 $\beta$ (golden brown) in association with the CBP80 (green)-CBP20 (blue) $\mathrm{CBC}$ heterodimer bound to $\mathrm{m}^{7} \mathrm{GpppA}$, which mimics the $\mathrm{m}^{7} \mathrm{G}$ cap linked $5^{\prime}-5$ ' to the first transcribed adenine nucleotide of an RNAPII-synthesized transcript. The CBP80-PGC-1 $\beta$ interface, including the 9-amino acid $\alpha$-helix that we defined as the CBP80-binding motif (CBM), is enlarged at the bottom. (B) Diagram of human PGC-1 $\alpha$ (WT) and PGC-1 $\alpha(\triangle \mathrm{CBM})$, denoting some of the known or putative functional regions. (RD) Repression domain, (AD) activation domain, (RS) serine-arginine-rich domain, (RRM) RNA-recognition motif, (CBM) CBP80-binding motif. Numbers pertain to amino acids. $(C)$ Schematic illustrating the strategy used to show that PGC- $1 \alpha$ binds the $5^{\prime}$ cap of three PGC- $1 \alpha$-activated transcripts. Annealing of a mix of three DNA oligonucleotides, each specific to the $5^{\prime}$ end of one of the transcripts, directed RNase H-mediated transcript cleavage so as to separate the $5^{\prime}$ cap (CAP) and associated CBC from each transcript body. (D) Histogram representation of RT-qPCR quantitations of PGC- $1 \alpha$-responsive pre-mRNA levels after, relative to before, anti-FLAG ( $\alpha$-FLAG) immunoprecipitation (IP) using lysates of PGC-1 $\alpha-\mathrm{KD}$ C2C12 MBs transiently transfected with plasmid (p) encoding FLAG alone (-) or the specified FLAG-tagged PGC-1 $\alpha$ (FLAG-PGC-1 $\alpha$ ) variant. IPs were performed in the presence of the oligonucleotide mix as described in $C$, either in the presence $(+)$ or absence $(-)$ of RNase H. Values after anti-FLAG-PGC-1 $\alpha(W T)$ IP in the absence of RNase H relative to before IP are set to 1 . Results are means \pm S.D. $n=2$. $(* *) P<0.01$, compared to no RNase H treatment by a two-tailed unpaired Student's $t$-test. $(E)$ Western blots of lysates of PGC-1 $\alpha-\mathrm{KD}$ C2C12 MBs transiently transfected with plasmid encoding FLAG alone ( - ) or the specified FLAG-tagged PGC-1 $\alpha$ variant before or after anti-FLAG IP, the latter in the presence $(+)$ of RNase I. $\beta$-actin serves to control for variations in loading and IP specificity. Here, as in subsequent western blots, the top left wedge denotes threefold serial dilutions of samples to provide semiquantitative analyses. $(F)$ Heatmap and hierarchical clustering of the expression of protein-coding genes using RNA sequencing (RNA-seq) analyses of the specified cells: wild-type (WT) C2C12 MBs expressing FLAG alone (-), or PGC-1 $\alpha-$ knockdown (KD) C2C12 MBs expressing FLAG alone (-), FLAG-PGC-1 $\alpha(\mathrm{WT})$, or FLAG-PGC-1 $\alpha(\Delta \mathrm{CBM})$. Only genes whose expression was significantly regulated following PGC- $1 \alpha \mathrm{KD}$ and significantly rescued by re-expression of FLAG-PGC- $1 \alpha(\mathrm{WT})$ and/or FLAG-PGC- $1 \alpha(\Delta \mathrm{CBM})$ are shown. The color key represents row-scaled average expression values $(n=3)$. $(A-F$, Modified from Cho et al. 2018.) 
or FLAG-PGC-1 $\alpha(\Delta \mathrm{CBM})$ (Fig. 1F; modified from Cho et al. 2018).

All of these data indicate that once PGC- $1 \alpha$ is recruited to the promoter, or enhancer, of a PGC- $1 \alpha$-activated gene, its interaction with CBP80 at the $5^{\prime}$ cap of the associated nascent transcript is key to gene expression (Cho et al. 2018). Should the nascent transcript fail to undergo $5^{\prime}$ capping or otherwise fail to acquire the $\mathrm{CBC}$, then the synthesis of full-length pre-mRNA and, therefore, the production of mRNA fail to occur (Cho et al. 2018). Thus, the PGC- $1 \alpha$ CBM can be viewed as key to one of the many steps involved in the quality control of PGC- $1 \alpha-$ activated gene expression, functioning as a type of premRNA surveillance. Whether PGC-1 $\alpha$ CBM-mediated transcriptional activation is a consequence of up-regulated transcription re-initiation or up-regulated transcription elongation has yet to be resolved. Given increasing evidence that overcoming promoter-proximal pausing is central to productive transcription initiation in higher eukaryotes (Core and Adelman 2019), we are currently testing the hypothesis that the PGC- $1 \alpha \mathrm{CBM}$, via its binding to $\mathrm{CBP} 80$ at the $5^{\prime}$ cap of nascent transcripts, promotes the release of RNAPII from promoter-proximal pausing on PGC- $1 \alpha$-activated genes. Additional open questions pertain to the functions of the carboxy-terminal RS domain and the RNA-recognition motif (RRM) of PGC- $1 \alpha$, both of which we found are required for the stable RNase-insensitive co-IP of CBP80 with PGC- $1 \alpha$ and, consequently, the association of PGC- $1 \alpha$ with its target transcripts (Cho et al. 2018).

\section{THE PGC-1 $\alpha$ CBM PREVENTS CYTOPLASMIC ACCUMULATION OF INTRON 1- CONTAINING mRNAS DERIVING FROM PGC-1 $\alpha$ CBM-ACTIVATED GENES}

Largely concomitant with pre-mRNA synthesis are the steps of pre-mRNA splicing. Another of our interests is how transcription factors and cofactors "imprint" nascent protein-coding transcripts to regulate their subsequent fate during splicing (Rambout et al. 2018). Beyond pre-mRNA splicing, previous work has focused on how transcript imprinting by the erythroblast transformation-specific transcription factor ERG conditionally regulates RNA metabolic steps that extend out into the cytoplasm so as to affect cytoplasmic mRNA stability (Rambout et al. 2016).

Returning to our long-standing interest in how NMD degrades newly spliced mRNAs on which the $\mathrm{CBC}$ has yet to be replaced by eIF4E (Lejeune et al. 2002) led us to test if the PGC- $1 \alpha$ CBM participates in NMD. This seemed to be reasonable considering that (i) PGC- $1 \alpha$ remains associated with CBC-bound mRNAs produced by PGC-1 $\alpha-$ responsive genes (Cho et al. 2018) and, as discussed above, (ii) 3'-UTR EJC-dependent NMD degrades cytoplasmic CBC-bound mRNAs.

In possible support of PGC- $1 \alpha$ function during NMD, one purpose of NMD is to function as a quality-control pathway that eliminates incompletely or improperly spliced transcripts (Jacob and Smith 2017). As an example, should an mRNA be incompletely spliced and exported to the cytoplasm, and should the retained intronic sequences introduce a frameshift mutation or nonsense codon that produces a PTC, the resulting intron-containing mRNA is likely to be degraded by NMD. Of course, the farther the retained intronic sequences reside relative to the 3' UTR, the greater the likelihood that these retained sequences result in a PTC upstream of 3'-UTR EJC. It follows that retained intron 1 sequences are most likely to trigger NMD.

The CBC promotes recognition of the cap-proximal 5 '-splice site (Lewis et al. 1996) so as to expedite the splicing of intron 1 (Bittencourt et al. 2008; Laubinger et al. 2008; Li et al. 2016b). And PGC-1 $\alpha$ has been shown to function in pre-mRNA splicing, albeit alternative premRNA splicing (Monsalve et al. 2000; Martínez-Redondo et al. 2016). Therefore, we began to investigate if the PGC$1 \alpha$ CBM functions in splicing and, possibly, NMD by analyzing the cytoplasmic-to-nuclear $(\mathrm{C} / \mathrm{N})$ ratios of intron 1-retained Idh $3 b, P f k l$, and Sirt 5 transcripts (Fig. 1), which we had shown are bound by PGC-1 $\alpha$ at their $5^{\prime}$ cap (Cho et al. 2018). We used WT C2C12 MBs expressing FLAG alone, or PGC-1 $\alpha-\mathrm{KD}$ C2C12 MBs expressing either FLAG alone, FLAG-PGC- $1 \alpha(\mathrm{WT})$, or FLAGPGC-1 $\alpha(\Delta \mathrm{CBM})$. As MB-fractionation controls, nucleoporin NUP160 and the glycolytic protein GAPDH were detectable only in nuclear and cytoplasmic fractions, respectively (Fig. 2A). Consistent with these results, U6 small nuclear (sn)RNA and Gapdh mRNA were enriched in nuclear and cytoplasmic fractions, respectively (Fig. 2B).

We previously reported that, relative to either WT $\mathrm{C} 2 \mathrm{C} 12 \mathrm{MBs}$ or $\mathrm{PGC} 1 \alpha-\mathrm{KD} \mathrm{C} 2 \mathrm{C} 12 \mathrm{MBs}$ expressing FLAG-PGC- $1 \alpha($ WT), PGC $1 \alpha-K D$ MBs expressing either FLAG alone or FLAG-PGC-1 $\alpha(\Delta \mathrm{CBM})$ produce abnormally low levels of normally spliced $I d h 3 b, P f k l$, and Sirt 5 mRNAs (Fig. 2C; adapted from Cho et al. 2018). However, we report here that accompanying these low levels are increased $\mathrm{C} / \mathrm{N}$ ratios of the corresponding intron 1-containing mRNAs (Fig. 2D), without detectable changes in the $\mathrm{C} / \mathrm{N}$ ratios of either intron 2- or intron 3-containing mRNAs (data not shown).

A PGC- $1 \alpha$ CBM-dependent decrease in the $\mathrm{C} / \mathrm{N}$ ratio of intron 1-containing mRNAs could be the result of increased mRNA stability in the nucleus, impaired nuclear mRNA export, and/or decreased mRNA stability in the cytoplasm (e.g., increased NMD). Supporting the hypothesis that the PGC- $1 \alpha$ CBM promotes NMD, inhibiting NMD by siRNA-mediated KD of the key NMD factor UPF1 (Fig. 2E) increased the cytoplasmic levels of each of the three intron 1-containing mRNAs, normalized to the non-NMD target Gapdh mRNA, in PGC1 $\alpha$ KD MBs expressing FLAG-PGC- $1 \alpha(\mathrm{WT})$ relative to PGC $1 \alpha-K D$ MBs expressing FLAG-PGC- $1 \alpha(\Delta C B M)$ (Fig. 2F). In other words, intron 1-containing mRNAs deriving from PGC- $1 \alpha$-activated genes and whose cap is not bound by PGC-1 $\alpha$ appear to evade the NMD surveillance mechanism and, as a result, accumulate in the cytoplasm. Altogether, our results indicate that the PGC1 $\alpha$ CBM (i) is required for efficient intron 1 splicing and (ii) 
A

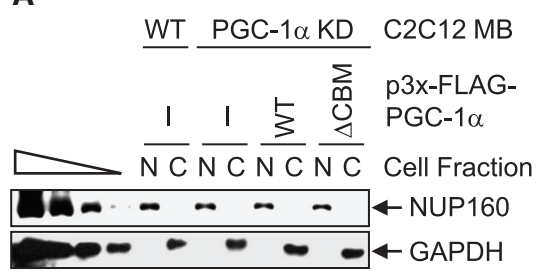

C

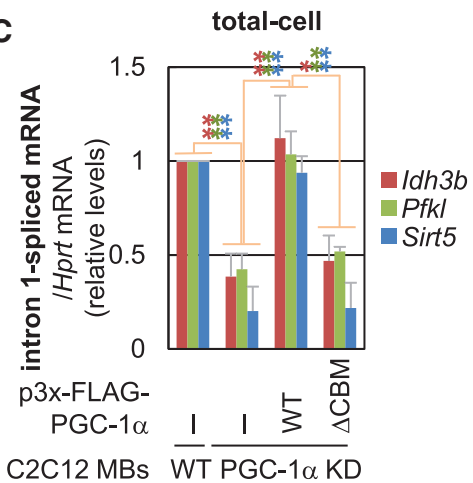

D
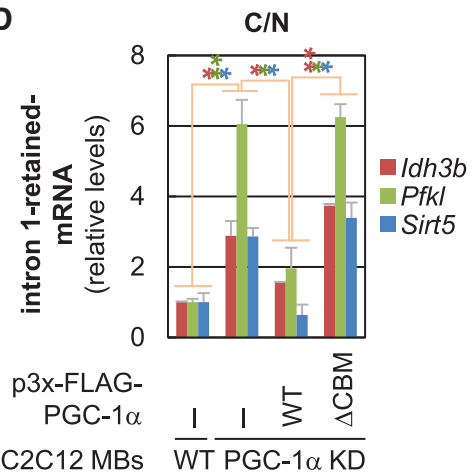

B

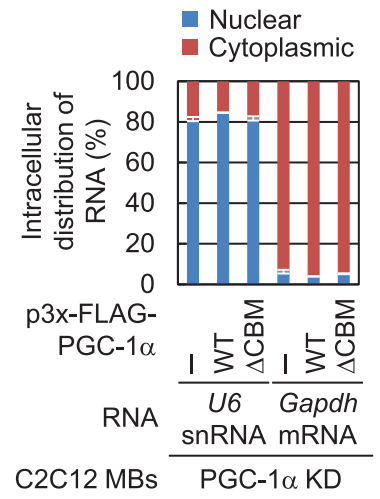

E

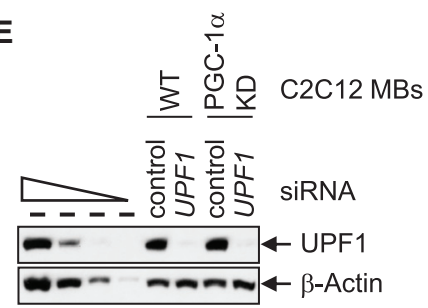

F cytoplasm (UPF1 SiRNA/ control siRNA)

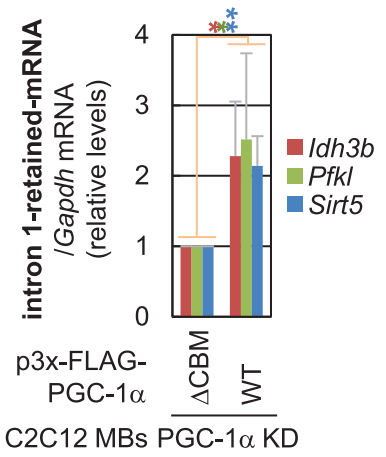

Figure 2. CBP80 binding to PGC-1 $\alpha$ reduces the cytoplasmic accumulation of intron 1 -containing transcripts deriving from PGC-1 $\alpha$ activated genes. $(A)$ Western blots of nuclear and cytoplasmic fractions from the same number of WT C2C12 MBs expressing FLAG alone $(-)$ or PGC- $1 \alpha-$ KD C2C12 MBs expressing FLAG alone $(-)$ or the denoted FLAG-PGC-1 $\alpha$ variant. NUP160 and GAPDH are nuclear pore and cytoplasmic constituents, respectively. (N) Nucleus, (C) cytoplasm. (B) Stacked histogram representation of RT-qPCR quantitations of the relative distribution of U6 snRNA (largely nuclear) and Gapdh mRNA (largely cytoplasmic) in the nuclear (blue) and cytoplasmic (red) fraction of cells treated as in $A$. Results are means \pm S.D. $n=2$. (C) Histogram representation of RT-qPCR quantitations of total-cell levels of three intron 1-spliced mRNAs deriving from PGC-1 $\alpha$ CBM-activated genes using cells treated as in $A$. Results are means \pm S.D. $n=3 .(*) P<0.05,(* *) P<0.01$ by a two-tailed unpaired Student's $t$-test. $(D)$ Histogram representation of RT-qPCR quantitations of cytoplasmic-to-nuclear $(\mathrm{C} / \mathrm{N})$ ratios of three intron 1-retained mRNAs deriving from PGC-1 $\alpha$ CBM-activated genes using cells treated as in $A$. Results are means \pm S.D. $n=2 .(*) P<0.05,(* *) P<0.01$ by a two-tailed unpaired Student's $t$-test. $(E)$ Western blot of lysates of WT or PGC-1 $\alpha-\mathrm{KD}$ C2C12 MBs transiently transfected with either control or UPF1 siRNA, demonstrating effective UPF1 KD to $\leq 10 \%$ of normal. $(F)$ Histogram representation of RT-qPCR quantitations of the cytoplasmic levels of three intron 1 -retained mRNAs deriving from PGC-1 $\alpha$ CBM-activated genes, normalized to the cytoplasmic level of Gapdh mRNA, using PGC$1 \alpha-\mathrm{KD}$ C2C12 MBs transiently transfected with UPF1 or control siRNA and, subsequently, FLAG-PGC-1 $\alpha($ WT) or FLAG-PGC-1 $\alpha$ $(\triangle \mathrm{CBM})$. Values for PGC-1 $\alpha-\mathrm{KD}$ C2C12 MBs expressing FLAG-PGC-1 $\alpha(\Delta \mathrm{CBM})$ are set to 1 . Results are means \pm S.D. $n=2$. $(*) P<$ $0.05,(* *) P<0.01$ by a two-tailed unpaired Student's $t$-test. Methods from which these data derive have been published elsewhere (Gong et al. 2009; Cho et al. 2018). (C, Modified from Cho et al. 2018.)

in cases where cytoplasmic intron 1-containing mRNAs are nonetheless produced, permits if not promotes their degradation by NMD. We do not exclude the possibility that PGC1 $\alpha$ via its CBM functions in other steps of gene expression, such as nuclear mRNA stability and export, that may also contribute to prevent the accumulation of intron 1-containing mRNAs.

\section{CONCLUSION}

Although NMD is arguably the best-characterized mechanism by which nuclear and cytoplasmic RNA processing machineries are coordinated so as to control the quality of protein-coding gene expression, it is clear there are additional connections to be discovered and 


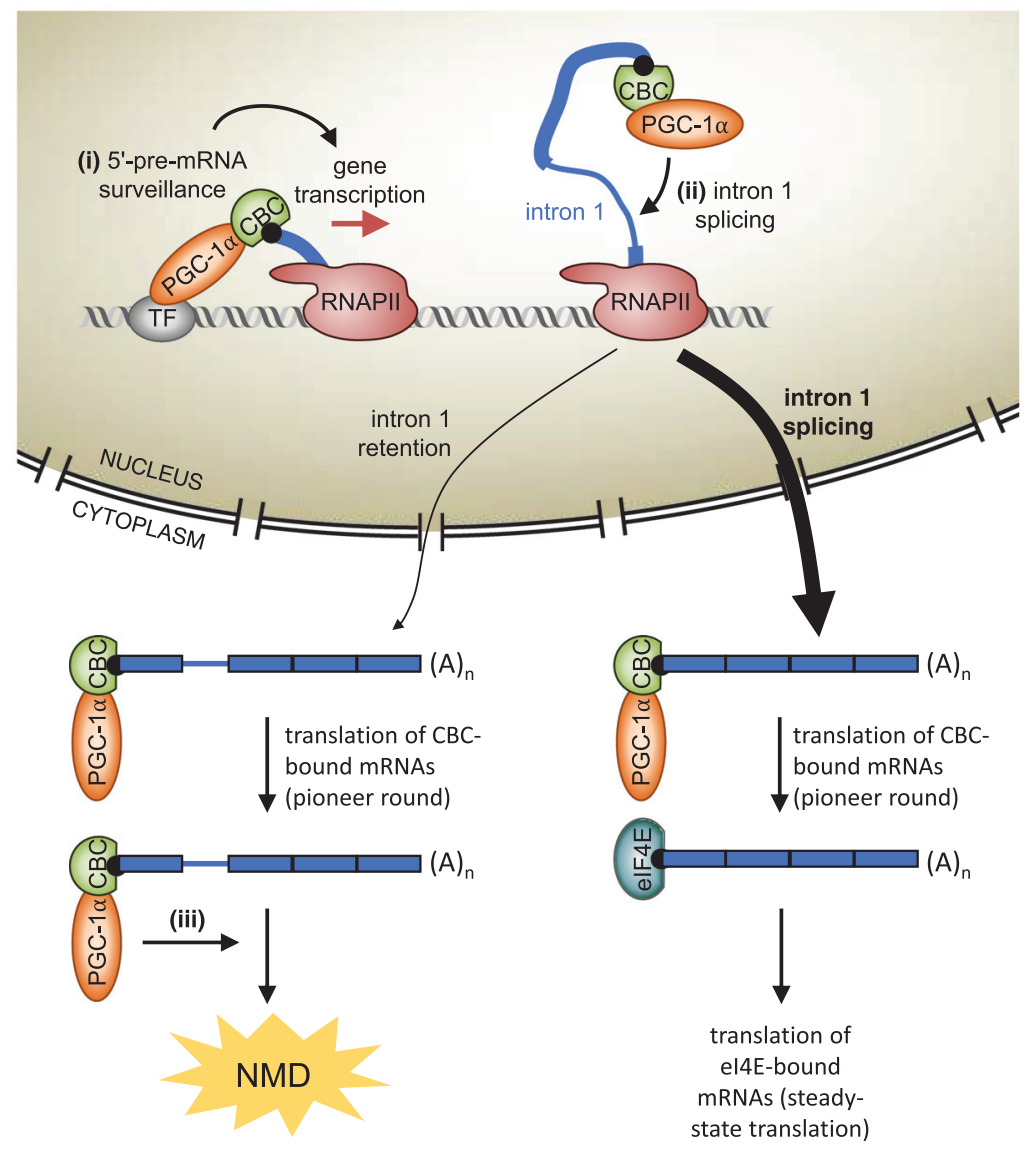

Figure 3. Model for PGC-1 $\alpha-$ CBP80-dependent coupling of co- and posttranscriptional steps of gene expression. PGC- $1 \alpha$ binding to CBP80 of the CBC promotes: (step i) target-gene transcription provided the nascent transcript has undergone proper 5'-end capping and CBC binding; (step ii) intron 1 splicing; and (step iii) NMD of cytoplasmic mRNAs in which intron 1 was mistakenly retained.

characterized. Work done by ourselves and others has shaped the current understanding of how CBP80 functions as a nexus for regulating co- and posttranscriptional RNA processes, forming a continuum that begins with transcription initiation in the nucleus and ends only when the CBC is replaced by eIF4E in the cytoplasm.

We recently showed that binding of the transcriptional coactivator PGC- $1 \alpha$ to CBP80 promotes the transcription of the majority of PGC-1 $\alpha$-activated genes (Cho et al. 2018). We see this interaction not only as a cue for increased gene transcription but also as a checkpoint that surveys the integrity of pre-mRNA 5 '-end capping and $\mathrm{CBC}$ acquisition (Fig. 3, step i). Beyond this function, we provide evidence that PGC- $1 \alpha$ binding to CBP 80 promotes intron 1 splicing (Fig. 3, step ii) and the NMD of intron 1-containing mRNAs (Fig. 3, step iii) deriving from PGC- $1 \alpha \mathrm{CBM}$-activated genes. Thus, our data indicate that PGC- $1 \alpha$ and CBP80 not only promote the transcription of target genes, but they also ensure that only 5 '-end-capped and properly spliced mRNAs accumulate in the cytoplasm where they can be translated into functional proteins. The failure of eIF4E to co-immunoprecipitate with PGC-1 $\alpha$ (Cho et al. 2018) indicates that PGC-1 $\alpha$ dissociates from the mRNA cap together with the $\mathrm{CBC}$ shortly after nuclear export and therefore does not take part in steady-state mRNA translation.

The mechanism by which PGC- $1 \alpha$ binding to CBP80 promotes gene transcription is currently unknown (see above), as is the mechanism by which PGC-1 $\alpha$ binding to CBP80 facilitates NMD. Possibilities for the latter include (i) enhanced translation initiation during the pioneer round of translation, (ii) increased recruitment of UPF1 to an NMD target, and/or (iii) differential recruitment of other positive or negative regulators of NMD. It should be noted that our RNA-seq data indicate that some PGC- $1 \alpha$ responsive genes are repressed rather than activated by the CBM (Fig. 1F, gene cluster \#6; modified from Cho et al. 2018). Analyses of previously published data deriving from chromatin immunoprecipitation coupled to sequencing (ChIP-seq) show that FLAG-tagged PGC- $1 \alpha$ is recruited to the promoter of at least some of these genes in C2C12 MBs (Baresic et al. 2014), raising the possibility that CBM-mediated gene repression may be direct. However, whether this repression is through inhibition of gene transcription or through coupling to pre-mRNA splicing and/or mRNA decay (e.g., NMD) remains to be tested.

Future studies will undoubtedly determine if other transcriptional coactivators function in pre-mRNA surveillance mechanisms. Whereas the CBM is conserved in 
all three members of the PGC-1 family of proteins, we failed to identify CBM-like motifs in other transcriptional coactivators or DNA-binding transcription factors (Cho et al. 2018). However, we recently reviewed the numerous ways by which transcription factors directly control alternative pre-mRNA splicing (Rambout et al. 2018). Thus, we anticipate that additional gene-specific chromatin-acting mediators of pre-mRNA surveillance pathways will be identified in the future.

\section{ACKNOWLEDGMENTS}

This work was supported by the American Heart Association (AHA) Postdoctoral Fellowships 18POST3 3960339 to X.R. and 16POST27260273 to H.C. and by the National Institutes of Health (NIH) grant R01 GM059514 to L.E.M.

\section{REFERENCES}

Aguilo F, Li S, Balasubramaniyan N, Sancho A, Benko S, Zhang F, Vashisht A, Rengasamy M, Andino B, Chen C-H, et al. 2016. Deposition of 5-methylcytosine on enhancer RNAs enables the coactivator function of PGC-1 $\alpha$. Cell Rep 14: 479492. doi: $10.1016 / \mathrm{j}$.celrep.2015.12.043

Allen BL, Taatjes DJ. 2015. The mediator complex: a central integrator of transcription. Nat Rev Mol Cell Biol 16: 155166. doi: $10.1038 / \mathrm{nrm} 3951$

Baresic M, Salatino S, Kupr B, van Nimwegen E, Handschin C. 2014. Transcriptional network analysis in muscle reveals AP-1 as a partner of PGC- $1 \alpha$ in the regulation of the hypoxic gene program. Mol Cell Biol 34: 2996-3012. doi:10.1128/MCB $.01710-13$

Bittencourt D, Dutertre M, Sanchez G, Barbier J, Gratadou L, Auboeuf D. 2008. Cotranscriptional splicing potentiates the mRNA production from a subset of estradiol-stimulated genes. Mol Cell Biol 28: 5811-5824. doi:10.1128/MCB.02231-07

Chen W, Yang Q, Roeder RG. 2009. Dynamic interactions and cooperative functions of PGC- $1 \alpha$ and MED1 in TR $\alpha$-mediated activation of the brown-fat-specific $U C P-1$ gene. Mol Cell 35: 755-768. doi:10.1016/j.molcel.2009.09.015

Cho H, Rambout X, Gleghorn ML, Nguyen PQT, Phipps CR, Miyoshi K, Myers JR, Kataoka N, Fasan R, Maquat LE. 2018. Transcriptional coactivator PGC-1 $\alpha$ contains a novel CBP80binding motif that orchestrates efficient target gene expression. Genes Dev 32: 555-567. doi:10.1101/gad.309773.117

Core L, Adelman K. 2019. Promoter-proximal pausing of RNA polymerase II: a nexus of gene regulation. Genes Dev 33: 960 982. doi: $10.1101 / \operatorname{gad} .325142 .119$

Correia JC, Ferreira DM, Ruas JL. 2015. Intercellular: local and systemic actions of skeletal muscle PGC-1s. Trends Endocrinol Metab 26: 305-314. doi:10.1016/j.tem.2015.03.010

Glover-Cutter K, Kim S, Espinosa J, Bentley DL. 2008. RNA polymerase II pauses and associates with pre-mRNA processing factors at both ends of genes. Nat Struct Mol Biol 15: 7178. doi:10.1038/nsmb1352

Gonatopoulos-Pournatzis T, Cowling VH. 2014. Cap-binding complex (CBC). Biochem J 457: 231-242. doi:10.1042/B J20131214

Gong C, Kim YK, Woeller CF, Tang Y, Maquat LE. 2009. SMD and NMD are competitive pathways that contribute to myogenesis: effects on PAX3 and myogenin mRNAs. Genes Dev 23: 54-66. doi:10.1101/gad.1717309

Hoek TA, Khuperkar D, Lindeboom RGH, Sonneveld S, Verhagen BMP, Boersma S, Vermeulen M, Tanenbaum ME. 2019. Single-molecule imaging uncovers rules governing nonsensemediated mRNA decay. Mol Cell 75: 324-339.e11. doi:10 .1016/j.molcel.2019.05.008
Hosoda N, Kim YK, Lejeune F, Maquat LE. 2005. CBP80 promotes interaction of Upf1 with Upf2 during nonsense-mediated mRNA decay in mammalian cells. Nat Struct Mol Biol 12: 893-901. doi:10.1038/nsmb995

Hossain MA, Chung C, Pradhan SK, Johnson TL. 2013. The yeast cap binding complex modulates transcription factor recruitment and establishes proper histone H3K36 trimethylation during active transcription. Mol Cell Biol 33: 785-799. doi:10.1128/MCB.00947-12

Hwang J, Sato H, Tang Y, Matsuda D, Maquat LE. 2010. UPF1 association with the cap-binding protein, CBP80, promotes nonsense-mediated mRNA decay at two distinct steps. Mol Cell 39: 396-409. doi:10.1016/j.molcel.2010.07.004

Ishigaki Y, Li X, Serin G, Maquat LE. 2001. Evidence for a pioneer round of mRNA translation: mRNAs subject to nonsense-mediated decay in mammalian cells are bound by CBP80 and CBP20. Cell 106: 607-617. doi:10.1016/S00928674(01)00475-5

Isken O, Kim YK, Hosoda N, Mayeur GL, Hershey JW, Maquat LE. 2008. Upf1 phosphorylation triggers translational repression during nonsense-mediated mRNA decay. Cell 133: 314 327. doi:10.1016/j.cell.2008.02.030

Jacob AG, Smith CWJ. 2017. Intron retention as a component of regulated gene expression programs. Hum Genet 136: $1043-$ 1057. doi:10.1007/s00439-017-1791-x

Kachaev ZM, Lebedeva LA, Shaposhnikov AV, Moresco JJ, Yates JR III, Schedl P, Shidlovskii YV. 2019. Paip2 cooperates with Cbp80 at an active promoter and participates in RNA polymerase II phosphorylation in Drosophila. FEBS Lett 593: 1102-1112. doi:10.1002/1873-3468.13391

Kataoka N, Ohno M, Moda I, Shimura Y. 1995. Identification of the factors that interact with NCBP, an $80 \mathrm{kDa}$ nuclear cap binding protein. Nucleic Acids Res 23: 3638-3641. doi:10 $.1093 /$ nar/23.18.3638

Kurosaki T, Popp MW, Maquat LE. 2019. Quality and quantity control of gene expression by nonsense-mediated mRNA decay. Nat Rev Mol Cell Biol 20: 406-420. doi:10.1038/s41580019-0126-2

Lahudkar S, Shukla A, Bajwa P, Durairaj G, Stanojevic N, Bhaumik SR. 2011. The mRNA cap-binding complex stimulates the formation of pre-initiation complex at the promoter via its interaction with Motlp in vivo. Nucleic Acids Res 39: 2188 2209. doi:10.1093/nar/gkq1029

Laubinger S, Sachsenberg T, Zeller G, Busch W, Lohmann JU, Ratsch G, Weigel D. 2008. Dual roles of the nuclear cap-binding complex and SERRATE in pre-mRNA splicing and microRNA processing in Arabidopsis thaliana. Proc Natl Acad Sci 105: 8795-8800. doi:10.1073/pnas.0802493105

Lee J, Salazar Hernández MA, Auen T, Mucka P, Lee J, Ozcan U. 2018. PGC-1 $\alpha$ functions as a co-suppressor of XBP1s to regulate glucose metabolism. Mol Metab 7: 119-131. doi:10 .1016/j.molmet.2017.10.010

Le Hir H, Moore MJ, Maquat LE. 2000. Pre-mRNA splicing alters mRNP composition: evidence for stable association of proteins at exon-exon junctions. Genes Dev 14: 1098-1108.

Lejeune F, Ishigaki Y, Li X, Maquat LE. 2002. The exon junction complex is detected on CBP80-bound but not eIF4E-bound mRNA in mammalian cells: dynamics of mRNP remodeling. EMBO J 21: 3536-3545. doi:10.1093/emboj/cdf345

Lenasi T, Peterlin BM, Barboric M. 2011. Cap-binding protein complex links pre-mRNA capping to transcription elongation and alternative splicing through positive transcription elongation factor b (P-TEFb). J Biol Chem 286: 22758-22768. doi:10.1074/jbc.M111.235077

Lewis JD, Izaurralde E, Jarmolowski A, McGuigan C, Mattaj IW. 1996. A nuclear cap-binding complex facilitates association of U1 snRNP with the cap-proximal 5' splice site. Genes Dev 10: 1683-1698. doi:10.1101/gad.10.13.1683

Li T, De Clercq N, Medina DA, Garre E, Sunnerhagen P, PerezOrtin JE, Alepuz P. 2016a. The mRNA cap-binding protein $\mathrm{Cbc1}$ is required for high and timely expression of genes by promoting the accumulation of gene-specific activators at pro- 
moters. Biochim Biophys Acta 1859: 405-419. doi:10.1016/j .bbagrm.2016.01.002

Li Z, Jiang D, Fu X, Luo X, Liu R, He Y. 2016b. Coupling of histone methylation and RNA processing by the nuclear mRNA cap-binding complex. Nat Plants 2: 16015. doi:10 .1038 /nplants.2016.15

Lidschreiber M, Leike K, Cramer P. 2013. Cap completion and $\mathrm{C}$-terminal repeat domain kinase recruitment underlie the initiation-elongation transition of RNA polymerase II. Mol Cell Biol 33: 3805-3816. doi:10.1128/MCB.00361-13

Listerman I, Sapra AK, Neugebauer KM. 2006. Cotranscriptional coupling of splicing factor recruitment and precursor messenger RNA splicing in mammalian cells. Nat Struct Mol Biol 13: 815-822. doi:10.1038/nsmb1135

Martínez-Redondo V, Pettersson AT, Ruas JL. 2015. The hitchhiker's guide to PGC-1 $\alpha$ isoform structure and biological functions. Diabetologia 58: 1969-1977. doi:10.1007/ s00125-015-3671-z

Martínez-Redondo V, Jannig PR, Correia JC, Ferreira DM, Cervenka I, Lindvall JM, Sinha I, Izadi M, Pettersson-Klein AT, Agudelo LZ, et al. 2016. Peroxisome proliferator-activated receptor $\gamma$ coactivator- $1 \alpha$ isoforms selectively regulate multiple splicing events on target genes. J Biol Chem 291: 15169 15184. doi:10.1074/jbc.M115.705822

Monsalve M, Wu Z, Adelmant G, Puigserver P, Fan M, Spiegelman BM. 2000. Direct coupling of transcription and mRNA processing through the thermogenic coactivator PGC-1. Mol Cell 6: 307-316. doi:10.1016/S1097-2765(00)00031-9
Pelletier J, Sonenberg N. 2019. The organizing principles of eukaryotic ribosome recruitment. Annu Rev Biochem 88: 307-335. doi:10.1146/annurev-biochem-013118-111042

Puigserver P, Adelmant G, Wu Z, Fan M, Xu J, O’Malley B, Spiegelman BM. 1999. Activation of PPAR $\gamma$ coactivator-1 through transcription factor docking. Science 286: 13681371. doi:10.1126/science.286.5443.1368

Rambout X, Detiffe C, Bruyr J, Mariavelle E, Cherkaoui M, Brohée S, Demoitié P, Lebrun M, Soin R, Lesage B, et al. 2016. The transcription factor ERG recruits CCR4-NOT to control mRNA decay and mitotic progression. Nat Struct Mol Biol 23: 663-672. doi:10.1038/nsmb.3243

Rambout X, Dequiedt F, Maquat LE. 2018. Beyond transcription: roles of transcription factors in pre-mRNA splicing. Chem Rev 118: 4339-4364. doi:10.1021/acs.chemrev.7b00470

Trcek T, Sato H, Singer RH, Maquat LE. 2013. Temporal and spatial characterization of nonsense-mediated mRNA decay. Genes Dev 27: 541-551. doi:10.1101/gad.209635.112

Wallberg AE, Yamamura S, Malik S, Spiegelman BM, Roeder RG. 2003. Coordination of p300-mediated chromatin remodeling and TRAP/mediator function through coactivator PGC1\%. Mol Cell 12: 1137-1149. doi:10.1016/S1097-2765(03) 00391-5

Xiao R, Chen J-Y, Liang Z, Luo D, Chen G, Lu ZJ, Chen Y, Zhou B, Li H, Du X, et al. 2019. Pervasive chromatin-RNA binding protein interactions enable RNA-based regulation of transcription. Cell 178: 107-121.e18. doi:10.1016/j.cell.2019.06.001 


\title{
$\$_{\mathrm{CSH}}^{\infty}$ Cold Spring Harbor Symposia SYMPOSIA on Quantitative Biology
}

\section{Transcriptional Coactivator PGC-1 $\alpha$ Binding to Newly Synthesized RNA via CBP80: A Nexus for Co- and Posttranscriptional Gene Regulation}

\author{
Xavier Rambout, Hana Cho and Lynne E. Maquat
}

Cold Spring Harb Symp Quant Biol published online April 15, 2020

Access the most recent version at doi:10.1101/sqb.2019.84.040212

\begin{tabular}{|c|c|}
\hline $\mathbf{P}<\mathbf{P}$ & Published online April 15, 2020 in advance of the print journal. \\
\hline $\begin{array}{r}\text { Creative } \\
\text { Commons } \\
\text { License }\end{array}$ & $\begin{array}{l}\text { This article is distributed under the terms of the } \\
\text { http://creativecommons.org/licenses/by-nc/4.0/, which permits reuse and } \\
\text { redistribution, except for commercial purposes, provided that the original } \\
\text { author and source are credited. }\end{array}$ \\
\hline $\begin{array}{l}\text { Email Alerting } \\
\text { Service }\end{array}$ & $\begin{array}{l}\text { Receive free email alerts when new articles cite this article - sign up in } \\
\text { the box at the top right corner of the article or click here. }\end{array}$ \\
\hline
\end{tabular}

Advance online articles have been peer reviewed and accepted for publication but have not yet appeared in the paper journal (edited, typeset versions may be posted when available prior to final publication). Advance online articles are citable and establish publication priority; they are indexed by PubMed from initial publication. Citations to Advance online articles must include the digital object identifier (DOIs) and date of initial publication.

To subscribe to Cold Spring Harbor Symposia on Quantitative Biology go to: http://symposium.cshlp.org/subscriptions 